Article

\title{
Intake of Red and Processed Meat, Use of Non-Steroid Anti-Inflammatory Drugs, Genetic Variants and Risk of Colorectal Cancer: A Prospective Study of the Danish "Diet, Cancer and Health" Cohort
}

\author{
Vibeke Andersen $1,2,3, * \mathbb{D}$, Ulrich Halekoh ${ }^{4}$, Anne Tjønneland ${ }^{5}$, Ulla Vogel ${ }^{6}$ and \\ Tine Iskov Kopp ${ }^{5,7}$ (D) \\ 1 Focused Research Unit for Molecular Diagnostic and Clinical Research, Institute of Regional Health \\ Research-Center Sønderjylland, Hospital of Southern Jutland, 6200 Aabenraa, Denmark \\ 2 Institute of Molecular Medicine, University of Southern Denmark, 5000 Odense, Denmark \\ 3 Institute of Regional Health Research, University of Southern Denmark, 5000 Odense, Denmark \\ 4 Institute of Public Health, Unit of Epidemiology and Biostatistics, University of Southern Denmark, \\ 5000 Odense, Denmark; uhalekoh@health.sdu.dk \\ 5 Danish Cancer Society Research Center, 2100 Copenhagen, Denmark; annet@cancer.dk \\ 6 National Research Centre for the Working Environment, 2100 Copenhagen, Denmark; UBV@nfa.dk \\ 7 The Danish Multiple Sclerosis Registry, Department of Neurology, Copenhagen University Hospital, \\ Rigshospitalet, 2200 Copenhagen, Denmark; tine.iskov.kopp@regionh.dk \\ * Correspondence: va@rsyd.dk; Tel.: +45-2115-7790
}

Received: 8 February 2019; Accepted: 27 February 2019; Published: 5 March 2019

\begin{abstract}
Red and processed meat have been associated with increased risk of colorectal cancer (CRC), whereas long-term use of non-steroid anti-inflammatory drugs (NSAIDs) may reduce the risk. The aim was to investigate potential interactions between meat intake, NSAID use, and gene variants in fatty acid metabolism and NSAID pathways in relation to the risk of CRC. A nested case-cohort study of 1038 CRC cases and 1857 randomly selected participants from the Danish prospective "Diet, Cancer and Health" study encompassing 57,053 persons was performed using the Cox proportional hazard model. Gene variants in SLC25A20, PRKAB1, LPCAT1, PLA2G4A, ALOX5, PTGER3, TP53, CCAT2, TCF7L2, and BCL2 were investigated. CCAT2 rs6983267 was associated with the risk of CRC per se $(p<0.01)$. Statistically significant interactions were found between intake of red and processed meat and CCAT2 rs6983267, TP53 rs1042522, LPCAT1 rs7737692, SLC25A20 rs7623023 $\left(p_{\text {interaction }}=0.04,0.04,0.02,0.03\right.$, respectively $)$, and the use of NSAID and alcohol intake and TP53 rs1042522 ( $p_{\text {interaction }}=0.04,0.04$, respectively) in relation to the risk of CRC. No other consistent associations or interactions were found. This study replicated an association of CCAT2 rs6983267 with CRC and an interaction between TP53 rs1042522 and NSAID in relation to CRC. Interactions between genetic variants in fatty acid metabolism and NSAID pathways and the intake of red and processed meat were found. Our results suggest that meat intake and NSAID use affect the same carcinogenic mechanisms. All new findings should be sought replicated in independent prospective studies. Future studies on the cancer-protective effects of aspirin/NSAID should include gene and meat assessments.
\end{abstract}

Keywords: gene-environment interaction; diet; colorectal cancer; candidate gene; red and processed meat; non-steroid anti-inflammatory drugs (NSAIDs); aspirin; Western-style diet 


\section{Introduction}

Colorectal cancer (CRC) is the third most common malignant tumor and the fourth leading cause of cancer death worldwide with a lifetime risk in Western European and North American populations of around 5\% [1]. Multiple risk factors, both genetic and environmental, are involved in the etiology and prognosis of CRC [2]. Identification and characterization of the risk factors, their potential interactions, and the underlying biological mechanisms are requested as a basis for improving preventative strategies that may include identifying individuals who would most benefit from preventive strategies.

Epidemiological studies suggest that the high intake of red and particularly processed meat may increase the CRC risk [3], whereas long-term use of non-steroid anti-inflammatory drugs (NSAIDs) including aspirin (acetylic acid) may reduce the risk of CRC [4,5]. Investigations on the potential carcinogenic mechanisms of red and processed meat have suggested that meat may confer carcinogenesis by being a source of cooking mutations (heterocyclic amine, $\mathrm{N}$-nitroso compounds) formed during preparation [6], organic sulphur-containing proteins leading to a high content of $\mathrm{H}_{2} \mathrm{~S}$ in the intestinal lumen, a highly potent regulator of intestinal cell function including inflammation and cell death signalling [7] and/or microbial factors arising during storage [8]. Similarly, the underlying cancer protective mechanisms of NSAID have been investigated and both COX-2 dependent and COX-2 independent mechanisms have been suggested $[9,10]$.

Still, however, the mechanisms are incompletely understood. First of all, epidemiological studies are not suitable to evaluate CRC causality because of collinearity between the studied factors (intake of red and processed meat and NSAID) and other potential CRC risk factors (such as e.g., Western-style diet and high body mass index) that limit the ability to analytically isolate the independent effects of the studied factors [11]. Next, although animal studies may suggest important underlying biological mechanisms [12], results from animal studies may not apply to humans due to differences in the biology such as the metabolism of meat between animals and humans and because doses used in animals may not be transferable to human conditions [6]. Gene-environment (GxE) interaction analyses may overcome the methodological issues mentioned above. Indeed, the identification of an interaction between a genetic variant (functional or in linkage with a functional variant) in a gene that is chosen based on its biological function and an environmental factor suggests that both factors are involved in the same process. Using GxE interaction analysis, we have investigated potential mechanisms by which red and processed meat and NSAID may affect CRC carcinogenesis [13-21] (reviewed in [22-24]). Red and processed meat is a rich source of n-6 polyunsaturated fat that is converted into arachidonic acid after ingestion and further metabolized into several bioactive lipids that play critical roles in a variety of biologic processes involved in chronic inflammation and colorectal cancer. Conversely, NSAIDs including aspirin may reduce inflammation and CRC risk via similar and other pathways in relation to CRC $[22,23,25]$.

Thus, the aim of the present study was to investigate the association of polymorphisms in genes involved in fatty acid metabolism and NSAID pathway with CRC, and, furthermore, interactions between these polymorphisms and NSAID use and dietary factors focusing on the intake of red and processed meat in relation to CRC. The study cohort was the Danish "Diet, Cancer and Health" with prospectively collected lifestyle information encompassing 57,053 participants, whereof 1038 cases that developed CRC were compared to a sub-cohort of 1857 members using a nested case-cohort design. In addition to replicating earlier findings, this study found interactions between genetic variants in fatty acid metabolism and NSAID pathway and intake of red and processed meat suggesting that meat intake and NSAID use affect the same carcinogenic mechanisms.

\section{Results}

Figure 1 shows the flowchart of study participants. Table 1 shows the baseline characteristics of 1038 CRC cases and 1857 sub-cohort members including CRC risk factors. Among the controls, the genotype distributions of the studied polymorphisms were in Hardy-Weinberg equilibrium. In order 
to maximize the statistical power for the interactions analyses, the genotypes were combined assuming either a dominant model (SLC25A20 rs7623023, TP53 rs1042522, CCAT2 rs6983267, BCL2 rs2279115) or a recessive model (PRKAB1 rs4213, LPCAT1 rs7737692, PLA2G4A rs4402086, ALOX5 rs3780894, PTGER3 rs6685546, TCF7L2 rs7903146) based on the observed risk estimates.

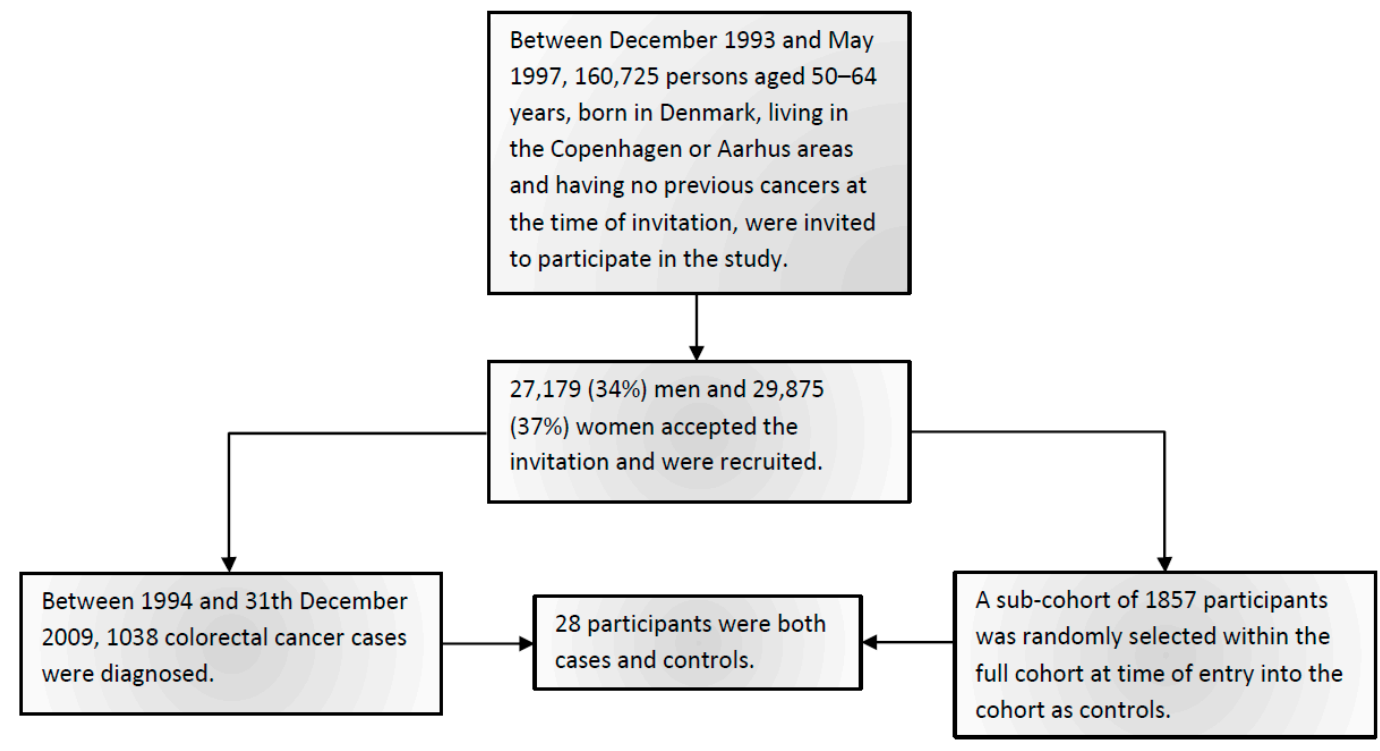

Figure 1. Flowchart of study participants.

Table 1. Participant description.

\begin{tabular}{|c|c|c|c|c|c|}
\hline Variable & \multicolumn{2}{|c|}{ Cases } & \multicolumn{2}{|c|}{ Sub-Cohort } & $\operatorname{IRR}(95 \% C I)^{1}$ \\
\hline Total & $1038(100)$ & & $1857(100)$ & & \\
\hline Females & $462(45)$ & & 865 (47) & & \\
\hline Males & $576(55)$ & & $992(53)$ & & \\
\hline Age at entry & & $58(51-65)$ & & $56(51-64)$ & \\
\hline Alcohol $(\mathrm{g} / \mathrm{d})^{2}$ & & $15(1-71)$ & & $14(1-66)$ & $1.03(0.98-1.07)^{5}$ \\
\hline Dietary fiber (g/d) & & $20(11-33)$ & & $21(11-34)$ & $0.83(0.65-1.08)^{6}$ \\
\hline $\begin{array}{l}\text { Red and processed meat } \\
(\mathrm{g} / \mathrm{d})\end{array}$ & & $112(46-233)$ & & $109(41-236)$ & $1.01(0.97-1.06)^{7}$ \\
\hline Total energy $(\mathrm{kJ} / \mathrm{d})$ & & $9681(6115-14712)[4]$ & & 9633 (5922-14820) & $1.00(1.00-1.00)^{8}$ \\
\hline Fruits $(\mathrm{g} / \mathrm{d})$ & & $166(24-493)[4]$ & & $176(27-546)$ & $0.98(0.95-1.02)^{9}$ \\
\hline Past & $322(31)$ & & $536(29)$ & & $1.12(0.91-1.38)$ \\
\hline Current & $410(39)$ & & $699(38)$ & & $1.18(0.97-1.44)$ \\
\hline \multicolumn{6}{|l|}{ NSAID use $^{3}$} \\
\hline No & $716(70)$ & & $1275(69)$ & & \\
\hline Yes & $313(30)$ & & $568(31)$ & & $0.99(0.84-1.18)$ \\
\hline \multicolumn{6}{|l|}{ HRT use among women } \\
\hline Never & $279(60)$ & & $455(53)$ & & \\
\hline Past & $62(13)$ & & $137(16)$ & & $0.65(0.45-0.92)$ \\
\hline Current & $121(26)$ & & $273(32)$ & & $0.70(0.53-0.92)$ \\
\hline
\end{tabular}

Values are expressed as medians (5th and 95th percentiles) or as fractions (\%). IRR, incidence rate ratio; CRC, colorectal cancer; CI, confidence interval; BMI, body mass index; NSAID, non-steroidal anti-inflammatory drug; HRT, hormone replacement therapy. ${ }^{1}$ IRRs for CRC estimated by the Cox proportional hazards model mutually adjusted for all variables, with age as the underlying time axis, and stratified by gender, so that the underlying hazards are gender specific. ${ }^{2}$ Among current drinkers. ${ }^{3}$ NSAID use is defined as $\geq 2$ pills per month for one year. ${ }^{4}$ Risk estimate per $2 \mathrm{~kg} / \mathrm{m} 2$ increment of BMI. ${ }^{5}$ Risk estimate for the increment of $10 \mathrm{~g}$ alcohol per day. ${ }^{6}$ Risk estimate for the increment of $10 \mathrm{~g}$ dietary fibers per day. ${ }^{7}$ Risk estimate for the increment of $25 \mathrm{~g}$ red and processed meat per day. ${ }^{8}$ Risk estimate for the increment of $1 \mathrm{~kJ}$ energy per day (incl alcohol). ${ }^{9}$ Risk estimate for the increment of 50 fruits per day. ${ }^{10}$ Risk estimate for the increment of 50 vegetables per day. ${ }^{11}$ Risk estimate for the increment of $50 \mathrm{~g}$ fruits or vegetables per day. 


\subsection{Associations between Polymorphisms and CRC}

Table 2 shows the crude associations between the SNPs and CRC. There was an association between CCAT2 rs6983267 and CRC $(p<0.01)$. Carriers of the CCAT2 rs6983267 variant T-allele had about $30 \%$ lower risk of CRC compared to GG homozygotes. No other statistically significant associations were found.

Table 2. Incidence rate ratios (IRR) for associations with colorectal cancer (CRC).

\begin{tabular}{|c|c|c|c|c|c|}
\hline Polymorphism & Ncases (\%) & Nsub-cohort (\%) & IRR $(95 \%$ CI) 1 & IRR $(95 \%$ CI) 2 & $p$-Value 3 \\
\hline \multicolumn{6}{|l|}{ SLC25A20 rs7623023 } \\
\hline AA & $368(39)$ & $701(40)$ & 1.00 (ref.) & 1.00 (ref.) & \\
\hline GA & $437(46)$ & $818(46)$ & $1.04(0.87-1.24)$ & $1.05(0.88-1.26)$ & 0.56 \\
\hline GG & $136(14)$ & $245(14)$ & $1.08(0.84-1.38)$ & $1.07(0.83-1.38)$ & 0.62 \\
\hline GA+GG & $573(61)$ & $1063(60)$ & $1.05(0.89-1.24)$ & $1.06(0.89-1.25)$ & 0.52 \\
\hline \multicolumn{6}{|l|}{ PRKAB1 rs4213 } \\
\hline TT & $454(48)$ & $875(50)$ & 1.00 (ref.) & 1.00 (ref.) & \\
\hline TG & $400(42)$ & $728(41)$ & $1.02(0.86-1.21)$ & $1.01(0.85-1.20)$ & 0.95 \\
\hline GG & $90(10)$ & $157(9)$ & $1.10(0.82-1.47)$ & $1.17(0.87-1.57)$ & 0.30 \\
\hline TG+GG & $490(52)$ & $885(50)$ & $1.03(0.88-1.22)$ & $1.03(0.88-1.22)$ & 0.70 \\
\hline GG vs. TT+TG & $90(10)$ & $157(9)$ & $1.09(0.82-1.44)$ & $1.17(0.88-1.55)$ & 0.29 \\
\hline \multicolumn{6}{|l|}{ LPCAT1 rs7737692 } \\
\hline AA & $378(40)$ & $762(43)$ & 1.00 (ref.) & 1.00 (ref.) & \\
\hline GA & $437(46)$ & $782(45)$ & $1.10(0.92-1.31)$ & $1.10(0.92-1.32)$ & 0.29 \\
\hline GG & $125(13)$ & $212(12)$ & $1.25(0.96-1.63)$ & $1.27(0.97-1.66)$ & 0.08 \\
\hline $\mathrm{GA}+\mathrm{GG}$ & $562(60)$ & $994(57)$ & $1.13(0.96-1.33)$ & $1.14(0.96-1.34)$ & 0.14 \\
\hline GG vs. AA+GA & $125(13)$ & $212(12)$ & $1.19(0.93-1.52)$ & $1.21(0.94-1.55)$ & 0.14 \\
\hline \multicolumn{6}{|l|}{ PLA2G4A rs4402086 } \\
\hline AA & $442(47)$ & $862(49)$ & 1.00 (ref.) & 1.00 (ref.) & \\
\hline GA & $405(43)$ & $758(43)$ & $1.04(0.88-1.23)$ & $1.02(0.86-1.22)$ & 0.79 \\
\hline GG & $87(9)$ & $141(8)$ & $1.22(0.91-1.65)$ & $1.23(0.91-1.66)$ & 0.19 \\
\hline $\mathrm{GA}+\mathrm{GG}$ & $492(53)$ & $899(51)$ & $1.07(0.91-1.26)$ & $1.06(0.89-1.25)$ & 0.53 \\
\hline \multirow{2}{*}{\multicolumn{6}{|c|}{ ALOX5 rs 3780894}} \\
\hline & & & & & \\
\hline AA & $676(72)$ & $1264(72)$ & 1.00 (ref.) & 1.00 (ref.) & \\
\hline GA & $231(25)$ & $463(26)$ & $0.93(0.77-1.13)$ & $0.92(0.76-1.12)$ & 0.43 \\
\hline GG & $27(3)$ & $38(2)$ & $1.37(0.81-2.29)$ & $1.38(0.81-2.35)$ & 0.24 \\
\hline GA+GG & $258(28)$ & $501(28)$ & $0.97(0.81-1.16)$ & $0.96(0.80-1.15)$ & 0.65 \\
\hline GG vs. AA+GA & $27(3)$ & $38(2)$ & $1.39(0.83-2.33)$ & $1.41(0.83-2.40)$ & 0.21 \\
\hline \multicolumn{6}{|l|}{ PTGER3 rs6685546 } \\
\hline TT & $637(68)$ & $1227(70)$ & 1.00 (ref.) & 1.00 (ref.) & \\
\hline TC & $276(29)$ & $485(28)$ & $1.14(0.95-1.37)$ & $1.15(0.96-1.39)$ & 0.14 \\
\hline CC & $28(3)$ & $48(3)$ & $0.95(0.58-1.55)$ & $0.97(0.59-1.60)$ & 0.92 \\
\hline $\mathrm{TC}+\mathrm{CC}$ & $304(32)$ & $533(30)$ & $1.12(0.94-1.34)$ & $1.13(0.95-1.36)$ & 0.18 \\
\hline \multirow{2}{*}{\multicolumn{6}{|c|}{ TP53 rs1042522 }} \\
\hline & & & & & \\
\hline GG & $517(55)$ & $962(55)$ & 1.00 (ref.) & 1.00 (ref.) & \\
\hline GC & $355(38)$ & 676 (38) & $0.99(0.83-1.17)$ & $0.99(0.83-1.18)$ & 0.89 \\
\hline $\mathrm{CC}$ & $63(7)$ & $120(7)$ & $0.94(0.67-1.31)$ & $1.00(0.71-1.40)$ & 1.00 \\
\hline \multirow{2}{*}{\multicolumn{6}{|c|}{ CCAT2 rs6983267 }} \\
\hline & & & & & \\
\hline GG & $315(34)$ & $479(27)$ & 1.00 (ref.) & 1.00 (ref.) & \\
\hline TG & $435(47)$ & $864(49)$ & $0.74(0.61-0.89)$ & $0.72(0.60-0.87)$ & $<0.01$ \\
\hline TT & $181(19)$ & $413(24)$ & $0.68(0.54-0.85)$ & $0.66(0.52-0.83)$ & $<0.01$ \\
\hline \multirow{2}{*}{\multicolumn{6}{|c|}{ TCF7L2 rs7903146 }} \\
\hline & & & & & \\
\hline CC & $492(53)$ & $916(52)$ & 1.00 (ref.) & 1.00 (ref.) & \\
\hline TC & $366(39)$ & $726(41)$ & $0.96(0.81-1.13)$ & $0.94(0.79-1.12)$ & 0.50 \\
\hline TT & $73(8)$ & $117(7)$ & $1.21(0.88-1.66)$ & $1.18(0.85-1.64)$ & 0.32 \\
\hline $\mathrm{TC}+\mathrm{TT}$ & $439(47)$ & $843(48)$ & $0.99(0.84-1.17)$ & $0.97(0.83-1.15)$ & 0.76 \\
\hline TT vs. $\mathrm{CC}+\mathrm{TC}$ & $73(8)$ & $117(7)$ & $1.23(0.90-1.68)$ & $1.21(0.88-1.66)$ & 0.24 \\
\hline \multicolumn{6}{|l|}{$B C L 2$ rs2279115 } \\
\hline AA & $280(31)$ & $508(29)$ & 1.00 (ref.) & 1.00 (ref.) & \\
\hline CA & $426(47)$ & $861(50)$ & $0.86(0.71-1.04)$ & $0.84(0.69-1.02)$ & 0.09 \\
\hline $\mathrm{CC}$ & $196(22)$ & $368(21)$ & $0.95(0.75-1.19)$ & $0.92(0.73-1.17)$ & 0.52 \\
\hline $\mathrm{CA}+\mathrm{CC}$ & $622(69)$ & $1229(71)$ & $0.89(0.74-1.06)$ & $0.87(0.72-1.04)$ & 0.13 \\
\hline
\end{tabular}

IRR, incidence rate ratio; CRC, colorectal cancer; CI, confidence interval; BMI, body mass index; NSAID, non-steroidal anti-inflammatory drug; HRT, hormone replacement therapy. ${ }^{1}$ IRRs for CRC estimated by the Cox proportional hazards model with age as the underlying time axis, and stratified by gender, so that the underlying hazards are gender specific. $95 \% \mathrm{CI}$ is based on Wald's tests. ${ }^{2}$ In addition, adjusted for smoking status, alcohol, HRT status (women only), BMI, use of NSAID, energy consumption, intake of red and processed meat dietary fiber, fruit and vegetable intake. ${ }^{3} p$-value for adjusted risk estimates. Number of missing values; SLC25A20 rs7623023 188, PRKAB1 rs4213 190, LPCAT1 rs7737692 198, PLA2G4A rs4402086 199, ALOX5 rs3780894 194, PTGER3 rs6685546 193, TP53 rs1042522 201, CCAT2 rs6983267 207, TCF7L2 rs7903146 203, BCL2 rs2279115 254. 


\subsection{Gene-Environmental Analyses}

Table 3 shows the interaction between NSAID and the polymorphisms. There was an interaction between use of NSAID and the TP53 rs1042522 polymorphism ( $\left.p_{\text {interaction }}=0.04\right)$. TP53 rs1042522 GG homozygotes had a lower relative risk of CRC for NSAID users to non-users compared to variant C-allele carriers.

Table 4 shows the interaction between dietary factors and the polymorphisms. Intake of red and processed meat interacted with CCAT2 rs6983267 ( $\left.p_{\text {interaction }}=0.04\right)$. CCAT2 $\mathrm{rs} 6983267$ T-allele carriers had a lower relative risk of CRC by meat intake compared to GG homozygotes. Furthermore, use of alcohol interacted with TP53 rs1042522 $\left(p_{\text {interaction }}=0.04\right)$. The variant C-allele carriers increased their risk for CRC with increased alcohol intake, whereas GG homozygotes did not. In the tertile analyses (Table S1), TP53 rs1042522 and LPCAT1 rs7737392 variant allele carriers had a higher risk increase than GG homozygotes ( $p_{\text {interaction }}=0.04$ and 0.02, respectively). Furthermore, SLC25A20 rs7623023 AA homozygotes had a higher risk increase than the variant G-carriers $\left(p_{\text {interaction }}=0.03\right.$ ) with increased meat intake. Variant allele carriers were at increased risk of CRC irrespectively of meat intake compared to the AA homozygotes. No other statistically significant interactions between diet or NSAID and the polymorphisms were found. 
Table 3. Interactions between polymorphisms and use of non-steroid anti-inflammatory drugs (NSAID).

\begin{tabular}{|c|c|c|c|c|c|c|c|}
\hline \multirow{2}{*}{ Polymorphism } & \multirow{2}{*}{$\begin{array}{l}\mathbf{N}_{\text {cases }} / \mathbf{N}_{\text {sub-cohort }} \\
\text { No }\end{array}$} & \multirow{2}{*}{$\begin{array}{l}\mathrm{N}_{\text {cases }} / \mathrm{N}_{\text {sub-cohort }} \\
\text { Yes }\end{array}$} & \multicolumn{2}{|c|}{${\text { IRR Crude }(95 \% \text { CI })^{1}}^{1}$} & \multicolumn{2}{|l|}{ IRR $\left(95 \%\right.$ CI) ${ }^{2}$} & \multirow{2}{*}{$p$-Value ${ }^{3}$} \\
\hline & & & No & Yes & No & Yes & \\
\hline \multicolumn{8}{|l|}{ SLC25A20 rs7623023 } \\
\hline AA & $241 / 469$ & $120 / 216$ & 1.00 & $1.09(0.83-1.45)$ & 1.00 & $1.07(0.80-1.42)$ & \\
\hline $\mathrm{GA}+\mathrm{GG}$ & $397 / 717$ & $159 / 320$ & $1.08(0.88-1.32)$ & $1.04(0.81-1.34)$ & $1.09(0.88-1.33)$ & $1.04(0.81-1.35)$ & 0.59 \\
\hline \multicolumn{8}{|l|}{ PRKAB1 rs4213 } \\
\hline $\mathrm{TT}+\mathrm{TG}$ & $585 / 1077$ & $246 / 489$ & 1.00 & $0.97(0.81-1.17)$ & 1.00 & $0.97(0.80-1.17)$ & \\
\hline \multicolumn{8}{|l|}{ LPCAT1 rs7737692 } \\
\hline $\mathrm{AA}+\mathrm{GA}$ & $556 / 1032$ & $241 / 473$ & 1.00 & $0.99(0.82-1.20)$ & 1.00 & $0.97(0.80-1.18)$ & \\
\hline GG & $80 / 148$ & $40 / 62$ & $1.07(0.79-1.44)$ & $1.34(0.88-2.06)$ & $1.06(0.78-1.44)$ & $1.41(0.92-2.17)$ & 0.26 \\
\hline \multicolumn{8}{|l|}{ PLA2G4A rs4402086 } \\
\hline \multicolumn{7}{|l|}{ ALOX5 rs3780894 } & 0.83 \\
\hline $\mathrm{AA}+\mathrm{GA}$ & $616 / 1157$ & $271 / 528$ & 1.00 & $1.01(0.84-1.21)$ & 1.00 & $1.00(0.83-1.20)$ & \\
\hline $\begin{array}{l}\text { GG } \\
\text { PTGER3 rs6685546 }\end{array}$ & $16 / 29$ & $8 / 9$ & $1.07(0.57-2.02)$ & $1.78(0.66-4.74)$ & $1.06(0.55-2.03)$ & $1.91(0.71-5.11)$ & 0.33 \\
\hline $\mathrm{TT}+\mathrm{TC}$ & $617 / 1151$ & $273 / 520$ & 1.00 & $1.01(0.85-1.21)$ & 1.00 & $1.01(0.84-1.21)$ & \\
\hline $\begin{array}{l}\text { CC } \\
\text { TP53 rs1042522 }\end{array}$ & $20 / 34$ & $7 / 13$ & $0.87(0.48-1.55)$ & $1.05(0.41-2.73)$ & $0.88(0.49-1.60)$ & $1.03(0.40-2.66)$ & 0.79 \\
\hline GG & $358 / 632$ & $145 / 308$ & 1.00 & $0.86(0.68-1.09)$ & 1.00 & $0.85(0.66-1.08)$ & \\
\hline \multicolumn{8}{|l|}{ CCAT2 rs6983267 } \\
\hline GG & $220 / 318$ & $86 / 152$ & 1.00 & $0.88(0.64-1.21)$ & 1.00 & $0.87(0.62-1.20)$ & \\
\hline TG+TT & $411 / 862$ & $190 / 383$ & $0.69(0.55-0.85)$ & $0.74(0.57-0.95)$ & $0.67(0.54-0.83)$ & $0.71(0.55-0.92)$ & 0.31 \\
\hline \multicolumn{8}{|l|}{ TCF7L2 rs7903146 } \\
\hline $\mathrm{CC}+\mathrm{TC}$ & $585 / 1104$ & $251 / 498$ & 1.00 & $1.00(0.83-1.20)$ & 1.00 & $0.98(0.81-1.19)$ & \\
\hline $\begin{array}{l}\text { TT } \\
B C L 2 \text { rs2279115 }\end{array}$ & $45 / 82$ & $27 / 33$ & $1.09(0.74-1.60)$ & $1.63(0.95-2.79)$ & $1.05(0.71-1.55)$ & $1.64(0.95-2.84)$ & 0.19 \\
\hline AA & $181 / 339$ & $87 / 159$ & 1.00 & $1.13(0.82-1.56)$ & 1.00 & $1.07(0.77-1.48)$ & \\
\hline $\mathrm{CA}+\mathrm{CC}$ & $427 / 833$ & $183 / 364$ & $0.95(0.76-1.18)$ & $0.96(0.74-1.24)$ & $0.91(0.73-1.14)$ & $0.93(0.71-1.21)$ & 0.82 \\
\hline
\end{tabular}

IRR, incidence rate ratio; CI, confidence interval; BMI, body mass index; NSAID, non-steroidal anti-inflammatory drug; HRT, hormone replacement therapy. ${ }^{1}$ IRRs for CRC estimated by the Cox proportional hazards model with age as the underlying time axis, and stratified by gender, so that the underlying hazards are gender specific. $95 \% \mathrm{CI}$ is based on Wald's tests. ${ }^{2}$ In addition, adjusted for smoking status, alcohol, HRT status (women only), BMI, use of NSAID, energy consumption, intake of red and processed meat, dietary fiber, intake of fruit and vegetable. ${ }^{3} p$-value for interaction on a multiplicative scale. Number of missing values; SLC25A20 rs7623023 254, PRKAB1 rs4213 257, LPCAT1 rs7737692 262, PLA2G4A rs4402086 266, ALOX5 rs3780894 259, PTGER3 rs6685546 259, TP53 rs1042522 266, CCAT2 rs6983267 272, TCF7L2 rs7903146 268, BCL2 rs2279115 320. 
Table 4. Interactions between polymorphisms and dietary factors.

\begin{tabular}{|c|c|c|c|c|c|c|c|c|}
\hline \multirow{2}{*}{ Polymorphism } & IRR $\left(95 \%\right.$ CI) ${ }^{1}$ & $p$-Value ${ }^{2}$ & IRR $(95 \% \text { CI })^{1}$ & $p$-Value ${ }^{2}$ & IRR $(95 \% \text { CI })^{1}$ & $p$-value ${ }^{2}$ & IRR $(95 \% \text { CI })^{1}$ & $p$-Value ${ }^{2}$ \\
\hline & \multicolumn{2}{|l|}{$\begin{array}{l}\text { Red and Processed } \\
\text { Meat ( } 25 \text { g/day) }\end{array}$} & \multicolumn{2}{|l|}{ Fiber (10 g/day) } & \multicolumn{2}{|l|}{$\begin{array}{l}\text { Fruit and Vegetables } \\
(50 \text { g/day })\end{array}$} & \multicolumn{2}{|l|}{ Alcohol (10 g/day) } \\
\hline \multicolumn{9}{|l|}{ SLC25A20 rs7623023 } \\
\hline $\mathrm{AA}$ & $1.02(0.96-1.08)$ & 0.64 & $0.87(0.64-1.18)$ & 0.85 & $0.98(0.95-1.02)$ & 0.60 & $1.02(0.95-1.08)$ & 0.76 \\
\hline \multicolumn{9}{|l|}{ PRKAB1 rs4213 } \\
\hline $\mathrm{TT}+\mathrm{TG}$ & $1.00(0.95-1.05)$ & 0.45 & $0.85(0.65-1.12)$ & 0.11 & $0.99(0.96-1.02)$ & 0.30 & $1.02(0.97-1.07)$ & 0.60 \\
\hline $\begin{array}{l}\text { GG } \\
\text { LPCAT1 rs7737692 }\end{array}$ & $1.05(0.93-1.18)$ & & $0.60(0.37-0.98)$ & & $0.96(0.90-1.02)$ & & $1.05(0.95-1.15)$ & \\
\hline $\mathrm{AA}+\mathrm{GA}$ & $1.02(0.97-1.07)$ & 0.06 & $0.88(0.67-1.16)$ & 0.09 & $0.99(0.96-1.02)$ & 0.65 & $1.02(0.97-1.07)$ & 0.87 \\
\hline GG & $0.92(0.84-1.02)$ & & $0.65(0.43-0.98)$ & & $0.98(0.93-1.03)$ & & $1.03(0.92-1.15)$ & \\
\hline \multicolumn{9}{|l|}{ PLA2G4A rs4402086 } \\
\hline $\mathrm{AA}+\mathrm{GA}$ & $1.01(0.96-1.06)$ & 0.66 & $0.88(0.67-1.16)$ & 0.92 & $0.99(0.96-1.02)$ & 0.92 & $1.03(0.98-1.08)$ & 0.74 \\
\hline \multicolumn{9}{|l|}{ ALOX5 rs3780894 } \\
\hline $\mathrm{AA}+\mathrm{GA}$ & $1.01(0.96-1.06)$ & 0.65 & $0.86(0.65-1.13)$ & 0.85 & $0.99(0.96-1.02)$ & 0.47 & $1.02(0.98-1.07)$ & 0.88 \\
\hline GG & $1.06(0.85-1.32)$ & & $0.80(0.39-1.67)$ & & $0.96(0.87-1.05)$ & & $1.07(0.65-1.75)$ & \\
\hline \multicolumn{9}{|l|}{ PTGER3 rs6685546 } \\
\hline $\mathrm{TT}+\mathrm{TC}$ & $1.01(0.96-1.06)$ & 0.23 & $0.85(0.65-1.11)$ & 0.85 & $0.99(0.96-1.02)$ & 0.90 & $1.02(0.98-1.07)$ & 0.64 \\
\hline CC & $0.91(0.77-1.08)$ & & $0.90(0.50-1.62)$ & & $0.99(0.91-1.08)$ & & $1.08(0.87-1.34)$ & \\
\hline \multicolumn{9}{|l|}{ TP53 rs1042522 } \\
\hline $\mathrm{GC}+\mathrm{CC}$ & $1.03(0.97-1.09)$ & 0.04 & $0.93(0.68-1.27)$ & 0.31 & $\begin{array}{l}1.00(0.96-1.03) \\
0.98(0.94-1.01)\end{array}$ & 0.31 & 1.08(1.01-1.16) & 0.04 \\
\hline \multicolumn{9}{|l|}{ CCAT2 rs6983267 } \\
\hline GG & $1.05(0.98-1.13)$ & 0.04 & $0.83(0.61-1.13)$ & 0.83 & $1.00(0.96-1.04)$ & 0.46 & $1.05(0.98-1.13)$ & 0.34 \\
\hline \multirow{2}{*}{\multicolumn{9}{|c|}{ TCF7L2 rs7903146 }} \\
\hline & & & & & & & & \\
\hline $\mathrm{CC}+\mathrm{TC}$ & $1.01(0.96-1.06)$ & 0.68 & $0.84(0.64-1.11)$ & 0.30 & $0.99(0.96-1.02)$ & 0.61 & $1.02(0.97-1.07)$ & 0.68 \\
\hline TT & $1.03(0.93-1.14)$ & & $1.10(0.65-1.87)$ & & $0.97(0.88-1.06)$ & & $1.05(0.92-1.20)$ & \\
\hline \multicolumn{9}{|l|}{$B C L 2$ rs 2279115} \\
\hline AA & $1.02(0.94-1.10)$ & 0.96 & $0.86(0.61-1.22)$ & 0.63 & $1.00(0.96-1.04)$ & 0.33 & $1.00(0.92-1.08)$ & 0.30 \\
\hline $\mathrm{CA}+\mathrm{CC}$ & $1.02(0.97-1.07)$ & & $0.92(0.70-1.22)$ & & $0.98(0.95-1.01)$ & & $1.05(0.99-1.10)$ & \\
\hline
\end{tabular}

IRR, incidence rate ratio; CRC, colorectal cancer; CI, confidence interval; BMI, body mass index; NSAID, non-steroidal anti-inflammatory drug; HRT, hormone replacement therapy. ${ }^{1}$ IRRs for CRC estimated by the Cox proportional hazards model with age as the underlying time axis, and stratified by gender, so that the underlying hazards are gender specific. Estimates are additionally adjusted for age, sex, smoking status, alcohol, HRT status (women only), BMI, use of NSAID, intake of red and processed meat, and dietary fiber. $95 \%$ CI is based on Wald's additionally adjusted for age, sex, smoking status, alcohol, HRT status (women only), BMI, use of NSAID, intake of red and processed meat, and dietary fiber. 95\% CI is based on Wald's
tests. ${ }^{2}$ p-value for interaction between genotype and dietary factor for adjusted risk estimates. Number of missing values; SLC25A20 rs7623023 254, PRKAB1 rs4213 257, LPCAT1 rs7737692 262, PLA2G4A rs4402086 266, ALOX5 rs3780894 259, PTGER3 rs6685546 259, TP53 rs1042522 266, CCAT2 rs6983267 272, TCF7L2 rs7903146 268, BCL2 rs2279115 320 


\section{Discussion}

This large prospective study investigated potential associations between polymorphisms in the fatty acid metabolic and NSAID pathways, and risk of CRC and, furthermore, the potential interaction between these polymorphisms and NSAID and diet (intake of red and processed meat, fiber, fruit and vegetables, and alcohol) in relation to CRC. The polymorphisms were selected from recent reviews based on their potential role in the fatty acid metabolic and NSAID pathways (Table 5) [22-24,26]. We found that CCAT2 rs6983267 GG genotype was associated with lowered risk of CRC per se and we found an interaction between the polymorphism and meat in relation to CRC. Furthermore, interactions between TP53 rs1042522 and use of NSAID, alcohol intake, and, in the tertile analysis, intake of red and processed meat was found. Next, we found interactions between LPCAT1 rs7737692 and SLC25A20 rs7623023 and intake of red and processed meat in the tertile analysis in relation to CRC. No other consistent associations or interactions were found.

Table 5. Suggested biological effects of the selected polymorphisms.

\begin{tabular}{|c|c|c|c|c|c|c|}
\hline $\begin{array}{l}\text { Expected } \\
\text { Interaction }\end{array}$ & SNP ID & $\begin{array}{l}\text { Nearby } \\
\text { Gene }\end{array}$ & Allele & MAF & Bio Effect & Ref \\
\hline Meat & rs7623023 & SLC25A20 & $\mathrm{G} / \mathrm{A}$ & 0.34 & $\begin{array}{l}\text { Carnitine acylcarnitine } \\
\text { translocase }\end{array}$ & [26] \\
\hline Meat & rs4213 & PRKAB1 & $\mathrm{G} / \mathrm{T}$ & 0.31 & $\begin{array}{l}\text { AMP-activated protein kinase } \\
\beta 1 \text { subunit }\end{array}$ & - \\
\hline Meat & rs7737692 & LPCAT1 & $\mathrm{G} / \mathrm{A}$ & 0.36 & $\begin{array}{l}\text { Lysophosphatidylcholine } \\
\text { acetyltransferase }\end{array}$ & - \\
\hline Meat & rs4402086 & $P L A 2 G 4 A$ & $\mathrm{G} / \mathrm{A}$ & 0.26 & Phospholipase A2 & - \\
\hline Meat & rs3780894 & ALOX5 & $\mathrm{G} / \mathrm{A}$ & 0.16 & Arachidonate 5-lipoxygenase & - \\
\hline Meat & rs6685546 & PTGER3 & $\mathrm{C} / \mathrm{T}$ & 0.14 & Prostaglandin E receptor 3 & - \\
\hline Aspirin & rs1042522 & TP53 & $\mathrm{C} / \mathrm{G}$ & 0.46 & $\mathrm{G}$ allele increase p53 level & {$[27,28]$} \\
\hline Aspirin & rs6983267 & CCAT2 & $\mathrm{G} / \mathrm{T}$ & 0.39 & $\begin{array}{l}\text { Aspirin suppresses the binding } \\
\text { of TCF7L } 2 \text { to the T allele }\end{array}$ & {$[22,29]$} \\
\hline Aspirin & rs7903146 & TCF7L2 & $\mathrm{T} / \mathrm{C}$ & 0.23 & $\begin{array}{l}\text { Intron, transcription factor that } \\
\text { plays a key role in the Wnt } \\
\text { signaling pathway }\end{array}$ & [22] \\
\hline Aspirin & rs2279115 & $B C L 2$ & $\mathrm{G} / \mathrm{F}$ & 0.46 & $\begin{array}{l}\text { Expression of BCL2 alternative } \\
\text { splicing transcripts (BCL2- } \alpha \text {, } \\
\text { BCL2- } \beta \text { ) in healthy donors }\end{array}$ & {$[27,30]$} \\
\hline
\end{tabular}

MAF, minor allele frequency; rs, reference SNP ID; SNP, single nucleotide polymorphism.

First, the association of CCAT2 rs6983267 with CRC confirmed earlier results from several independent populations [25,31] supporting the importance of the 8q24.21 gene locus for CRC carcinogenesis. The CCAT2 rs6983267 polymorphism is located in a non-protein coding region near the MYC gene. The T-allele of CCAT2 rs6983267 has been shown to impair binding of WNT/CTNNB1 pathway-related transcription factor 7 like-2 to DNA, thereby reducing MYC expression, which, in turn, induces resistance to intestinal tumorigenesis [25]. The polymorphism has also previously been found to interact with aspirin. Nan et al. found that variant T-allele carriers had $39-48 \%$ lower risk of CRC while using aspirin [25]. T-allele carriers of CCAT2 rs6983267 constitute $27 \%$ of the sub-cohort members in the present study. As we did not find an interaction between CCAT2 rs6983267 and NSAID use in the present study, the result may potentially suggest a specific effect of aspirin that may not be shared with non-aspirin NSAIDs in general. Unfortunately, the present study did not have the power to investigate aspirin use only.

Next, we found an interaction between TP53 rs1042522 and NSAID. In our study, GG homozygotes lowered their risk of CRC by use of NSAID, whereas variant C-allele carriers increased their risk of CRC by NSAID use $(p=0.04)$. This is a replication of an earlier finding [32]. Tan et al. observed that GG homozygotes benefitted more from the use of NSAID than variant C-allele carriers. They found a substantial protective effect of NSAID use for homozygous carriage of the 72Arg allele compared to the 72 Pro allele (odds ratio $0.44 ; 95 \%$ CI: 0.30-0.65) [32]. 
In the present study, four polymorphisms (CCAT2 rs6983267, TP53 rs1042522, LPCAT1 rs7737692, and SLC25A20 rs7623023) were found to interact with meat intake (Table 4 and Table S1). Two of the polymorphisms (SLC25A20 rs7623023 and LPCAT1 rs7737692) are involved in the metabolisms of fatty acids (Table 5); however, the functionality of the two common polymorphisms is unknown. The protein coded by LPCAT1 is involved in the remodelling of phospholipids and has been associated with risk of sudden cardiac arrest [26], whereas the protein coded by SLC25A20 is involved in the transport of fatty acids across the mitochondrial membrane. Our results may suggest that the fat from red and processed meat (that is metabolized to fatty acids) may contribute to the carcinogenic mechanism of red and processed meat in relation to CRC.

The two other polymorphisms (CCAT2 rs6983267 and TP53 rs1042522) have been found to interact with aspirin/NSAID in relation to CRC in the present or other studies [25,32]. TP53 rs1042522 is a missense polymorphism in the TP53 gene where Arginine is changed to Proline, which results in increased apoptosis potential due to increased p53 levels $[27,28]$. This polymorphism has been found to be associated with many different cancer types including breast cancer, lung cancer, endometrial cancer, non-Hodgkin lymphoma, esophageal squamous cell carcinoma, bladder cancer, ovarian cancer, neuroblastoma and hepatocellular carcinoma supporting its functionality. Several epidemiological studies, including randomized controlled clinical trials, have demonstrated that NSAID use decreases the incidence of adenomatous polyps and CRC [5]. The mechanism is thought to be caused by cell-cycle regulation and/or induction of apoptosis via mechanisms dependent and independent of cyclooxygenase [5,33]. The use of NSAID may enhance the apoptosis potential already present in the GG genotype of TP53 rs1042522 resulting in decreased risk of CRC compared to variant C-carriers. A diet high in meat was associated with increased risk of $C R C$ among variant $C$-allele carriers compared to those with a diet low in meat intake. We have previously shown that intake of meat interacts with polymorphisms in inflammatory genes in relation to CRC risk $[17,18,34]$, suggesting that a diet high in meat may cause an inflammatory milieu that increases the carcinogenic potential in persons with an impaired TP53 gene. This hypothesis could also apply for the CCAT2 rs6983267 polymorphism since persons homozygous for the G-allele have a higher expression of MYC [29] and thereby an increased carcinogenic potential, which could be further triggered by a diet high in meat. The finding that alcohol intake interacted with TP53 rs1042522 resulting in an increased risk of CRC for variant C-carriers may be caused by a similar mechanism as meat since alcohol is known to be associated with a systemic inflammatory state [35] and thus the protective effect of the G-allele is abolished.

Advantages and limitations with the study design have been described in previous studies [15-21]. The main advantage of this study is the prospective study design with the collection of dietary and lifestyle factors before diagnosis that eliminates the risk of recall bias. Another main advantage is the diverse and high intake of meat in the present cohort enabling identification of gene-meat interactions. The prospective "Diet, Cancer and Health" cohort has proven to be suitable to detect meat-gene interactions $[17,18,34]$. Changes in dietary and lifestyle habits during follow-up is possible, but, if present, will result in lower power to detect real differences between cases and the comparison group. The "Diet, Cancer and Health" cohort is homogenous reducing population specific genetics and dietary patterns seen in larger multicentre studies. The disadvantage of the prospective study is the limited power to study gene-environment interactions. None of the results withstood Bonferroni correction. Thus, all new findings should be replicated in independent prospective cohorts with well-characterized lifestyle information.

\section{Materials and Methods}

\subsection{Subjects}

As previously described [36], the "Diet, Cancer and Health" Study is an ongoing Danish cohort study designed to investigate the relation between diet, lifestyle and cancer risk. The cohort consists of 57,053 persons, recruited between December 1993 and May 1997. All the subjects were born in 
Denmark, and the individuals were 50 to 64 years of age and had no previous cancers at study entry. Blood samples, anthropometric measures and questionnaire data on diet and lifestyle were collected at study entry.

\subsection{Follow-up and Endpoints}

As previously described [20], the present study used a nested case-cohort design. Follow-up was based on population-based cancer registries. Between 1994 and 31 December 2009, 1038 CRC cases were diagnosed. A sub-cohort of 1857 persons was randomly selected within the full cohort at the time of entry into the cohort in agreement with the case-cohort study design [37] and, thus, without respect to time and disease status. Due to the study design, with a priori sampling of the sub-cohort, 28 persons were both cases and sub-cohort, and these persons were kept in the analyses. All 1038 CRC cases and 1857 sub-cohort members were included in the analysis. Flowchart of the participants is shown in Figure 1.

\subsection{Dietary and Lifestyle Questionnaire}

Information on diet, lifestyle, weight, height, medical treatment, environmental exposures, and other socio-economic factors were collected at enrolment using questionnaires and interviews and has been described in detail elsewhere [20,38]. In short, the food-frequency questionnaire, assessed diet consumption in 12 categories of predefined responses, ranking from 'never' to 'eight times or more per day'. The daily intake was then calculated by using FoodCalc [39]. Red meat was calculated by combining intake of fresh and minced beef, veal, pork, lamb, and offal, whereas processed meat combined intake of bacon, smoked or cooked ham, other cold cuts, salami, frankfurter, Cumberland sausage, and liver pâté. The total dietary fiber was estimated by the method of the Association of Official Analytical Chemists [40], which includes lignin and resistant starch. Fiber intake is calculated by multiplying the frequency of consumption of relevant foods (i.e., fruit, vegetables, grains, and leguminous fruit) by their fiber content as determined from national databases of food content. For fruit, only intake of fresh fruit was examined, whereas intake of vegetables also included estimated contributions from food recipes. Intake of alcohol was inferred from the food-frequency questionnaire and lifestyle questionnaire as described in detail in [41]. Abstainers were defined as those who reported no intake of alcohol on the food-frequency questionnaire and no drinking occasions on the lifestyle questionnaire. Smoking status was classified as never, past or current. Persons smoking at least 1 cigarette daily during the last year were classified as smokers. NSAID use ("Aspirin", "Ibuprofen", or "Other pain relievers) was assessed as $\geq 2$ pills per month during one year at baseline. Use of hormone replacement therapy among women was assessed as current, former or never user.

\subsection{Genotyping and Selection of Polymorphisms}

The polymorphisms were chosen based on Andersen et al. [22] and Lemaitre et al. [26]. Promising polymorphisms with known functionality or that were associated with biological effects suggesting functionality or linkage with functional polymorphism and with a reasonable minor allele frequency to study gene-environment interactions were selected. Buffy coat preparations were stored at minus $150^{\circ} \mathrm{C}$ until use. DNA was extracted as described [42]. The DNA was genotyped by LGC KBioscience (LGC KBioscience, Hoddesdon, UK) by PCR-based KASP ${ }^{\mathrm{TM}}$ genotyping assay (lgcgenomics.com/). To confirm reproducibility, genotyping was repeated for $10 \%$ of the samples, yielding $100 \%$ identity.

\subsection{Statistics}

Incidence rate ratios (IRR) and 95\% Confidence Interval (CI) were based on a Cox proportional hazard model fitted to the age at the event of CRC according to the principles for analysis of case-cohort [37] using the approach of Prentice and Langholz [43]. The main explanatory variables were the polymorphisms. All models were adjusted for baseline values of risk factors for CRC as published previously [17-21,34]; body mass index (BMI) $\left(\mathrm{kg} / \mathrm{m}^{2}\right.$, continuous), use of hormone 
replacement therapy, (never/past/current, among women), intake of dietary fiber (g/day, continuous), red and processed red meat (g/day, continuous), energy intake (kJ/day), NSAID use (yes/no) and smoking status (never/past/current). Cereals, fiber, fruit, and vegetables were also entered linearly as continuous covariates. All analyses were stratified by gender so that the basic (underlying) hazards were gender specific.

In the interaction analyses of the dietary factors with polymorphisms, we present two analyses: in one analysis, the dietary factors were used as numeric variables and, in the other, they were entered in the models as a three-level categorical variable defined via tertile cut points derived from the empirical distribution of the whole population. Information on numbers of missing observations on lifestyle data and genetics are included the individual tables. In addition, for the interaction analyses, all abstainers of alcohol were excluded from the analyses. Deviation from Hardy-Weinberg equilibrium in the comparison group was assessed using a chi-square test. All analyses were performed using the survival package (Terry M. Therneau, version 2.42.4) of the statistical computational environment $R$, version 3.5.1. A $p<0.05$ was considered to indicate a statistically significant test result.

\subsection{Ethics}

All participants gave verbal and written informed consent. The Diet, Cancer and Health study was approved (25 February 1991) by the National Committee on Health Research Ethics (journal nr. (KF) 01-345/93) and the Danish Data Protection Agency.

\section{Conclusions}

In conclusion, in this study, an association of CCAT2 rs6983267 with CRC and an interaction between TP53 rs1042522 and NSAID in relation to CRC were replicated. Our exploratory analyses found interactions between polymorphisms in the fatty acid metabolic pathway (LPCAT1 s7737692 and SLC25A20 rs7623023) and polymorphisms that have been found to interact with NSAID/aspirin (CCAT2 rs6983267 and TP53 rs1042522) on one hand and intake of red and processed meat on the other in relation to risk of CRC. Our results suggest that meat intake and NSAID use affect the same carcinogenic mechanisms. All new findings from this study should be replicated in independent prospective cohorts with well-characterized lifestyle information. Future studies on the cancer-protective effects of aspirin/NSAID should include gene and meat assessments.

Supplementary Materials: Supplementary Materials can be found at http:/ / www.mdpi.com/1422-0067/20/5/ $1121 /$ s1.

Author Contributions: U.H. performed the statistical analyses, V.A. wrote the first draft of the manuscript. V.A., T.I.K. and U.V. conceived the study, T.I.K. and V.A. interpreted the data and critically revised the manuscript for important intellectual content; V.A. obtained funding. A.T. designed the cohort study and collected the biological material. All authors commented on the work and accepted the final manuscript.

Funding: The project was supported by "Familien Erichsens Mindefond", "Købmand Sven Hansen og hustru Ina Hansens Fond" and "Knud og Edith Eriksens Mindefond". The funders had no role in the design of the study; in the collection, analyses, or interpretation of data; in the writing of the manuscript, or in the decision to publish the results.

Acknowledgments: We thank Katja Boll for technical assistance with data managing.

Conflicts of Interest: V.A. reports the receipt of compensation for consultancy and for being a member of an advisory board for M.S.D. (Merck, City, US State abbrev. if appropriate, Country) and Janssen. T.I.K., U.H., and U.V. report no conflicts of interests. 


\section{Abbreviations}

$\begin{array}{ll}\text { NSAID } & \text { Non-steroid anti-inflammatory drugs } \\ \text { CRC } & \text { Colorectal cancer } \\ \text { GxE } & \text { Gene-environment } \\ \text { BMI } & \text { Body mass index } \\ \text { IRR } & \text { Incidence rate ratios } \\ \text { CI } & \text { Confidence Interval }\end{array}$

\section{References}

1. World Cancer Research Fund/American Institute for Cancer Research. Food, Nutrition, Physical Activity, and the Prevention of Cancer: A Global Perspective, AIRC. 2018. Available online: https:/ /www.Wcrf.Org/ dietandcancer/colorectal-cancer (accessed on 2 March 2019).

2. Huxley, R.R.; Nsary-Moghaddam, A.; Clifton, P.; Czernichow, S.; Parr, C.L.; Woodward, M. The impact of dietary and lifestyle risk factors on risk of colorectal cancer: A quantitative overview of the epidemiological evidence. Int. J. Cancer 2009, 125, 171-180. [CrossRef] [PubMed]

3. Bouvard, V.; Loomis, D.; Guyton, K.Z.; Grosse, Y.; Ghissassi, F.E.; Benbrahim-Tallaa, L.; Guha, N.; Mattock, H.; Straif, K. Carcinogenicity of consumption of red and processed meat. Lancet Oncol. 2015, 16, 1599-1600. [CrossRef]

4. Friis, S.; Riis, A.H.; Erichsen, R.; Baron, J.A.; Sorensen, H.T. Low-dose aspirin or nonsteroidal anti-inflammatory drug use and colorectal cancer risk: A population-based, case-control study. Ann. Intern. Med. 2015, 163, 347-355. [CrossRef] [PubMed]

5. Huls, G.; Koornstra, J.J.; Kleibeuker, J.H. Non-steroidal anti-inflammatory drugs and molecular carcinogenesis of colorectal carcinomas. Lancet 2003, 362, 230-232. [CrossRef]

6. Santarelli, R.L.; Pierre, F.; Corpet, D.E. Processed meat and colorectal cancer: A review of epidemiologic and experimental evidence. Nutr. Cancer. 2008, 60, 131-144. [CrossRef] [PubMed]

7. Szabo, C. A timeline of hydrogen sulfide (H2S) research: From environmental toxin to biological mediator. Biochem. Pharmacol. 2017, 149, 5-19. [CrossRef] [PubMed]

8. Erridge, C. Accumulation of stimulants of toll-like receptor (TLR)-2 and TLR4 in meat products stored at 5 ${ }^{\circ}$ C. J. Food Sci. 2011, 76, H72-H79. [CrossRef] [PubMed]

9. Wang, Y.; Du, C.; Zhang, N.; Li, M.; Liu, Y.; Zhao, M.; Wang, F.; Luo, F. TGF- $\beta 1$ mediates the effects of aspirin on colonic tumor cell proliferation and apoptosis. Oncol. Lett. 2018, 15, 5903-5909. [CrossRef] [PubMed]

10. Wang, D.; DuBois, R.N. The role of anti-inflammatory drugs in colorectal cancer. Annu. Rev. Med. 2013, 64, 131-144. [CrossRef] [PubMed]

11. Alexander, D.D.; Cushing, C.A. Red meat and colorectal cancer: A critical summary of prospective epidemiologic studies. Obes. Rev. 2011, 12, e472-e493. [CrossRef] [PubMed]

12. Le Leu, R.K.; Young, G.P.; Hu, Y.; Winter, J.; Conlon, M.A. Dietary red meat aggravates dextran sulfate sodium-induced colitis in mice whereas resistant starch attenuates inflammation. Dig. Dis. Sci. 2013, 58, 3475-3482. [CrossRef] [PubMed]

13. Andersen, V.; Christensen, J.; Overvad, K.; Tjonneland, A.; Vogel, U. Heme oxygenase-1 polymorphism is not associated with risk of colorectal cancer: A Danish prospective study. Eur. J. Gastroenterol. Hepatol. 2011, 23, 282-285. [CrossRef] [PubMed]

14. Andersen, V.; Christensen, J.; Overvad, K.; Tjonneland, A.; Vogel, U. Polymorphisms in nfkb, pxr, lxr and risk of colorectal cancer in a prospective study of danes. BMC Cancer 2010, 10, 484. [CrossRef] [PubMed]

15. Andersen, V.; Egeberg, R.; Tjonneland, A.; Vogel, U. Interaction between interleukin-10 (IL-10) polymorphisms and dietary fibre in relation to risk of colorectal cancer in a Danish case-cohort study. BMC Cancer 2012, 12, 183. [CrossRef] [PubMed]

16. Andersen, V.; Egeberg, R.; Tjonneland, A.; Vogel, U. ABCC2 transporter gene polymorphisms, diet and risk of colorectal cancer: A Danish prospective cohort study. Scand. J. Gastroenterol. 2012, 47, 572-574. [CrossRef] [PubMed]

17. Andersen, V.; Holst, R.; Kopp, T.I.; Tjonneland, A.; Vogel, U. Interactions between diet, lifestyle and IL10, IL1B, and PTGS2/COX-2 gene polymorphisms in relation to risk of colorectal cancer in a prospective Danish case-cohort study. PLoS ONE 2013, 8, e78366. [CrossRef] [PubMed] 
18. Kopp, T.I.; Andersen, V.; Tjonneland, A.; Vogel, U. Polymorphisms in NFKB1 and TLR4 and interaction with dietary and life style factors in relation to colorectal cancer in a Danish prospective case-cohort study. PLoS ONE 2015, 10, e0116394. [CrossRef] [PubMed]

19. Kopp, T.I.; Andersen, V.; Tjonneland, A.; Vogel, U. Polymorphisms in ATP-binding cassette transporter genes and interaction with diet and life style factors in relation to colorectal cancer in a Danish prospective case-cohort study. Scand. J. Gastroenterol. 2015, 50, 1469-1481. [CrossRef] [PubMed]

20. Kopp, T.I.; Vogel, U.; Tjonneland, A.; Andersen, V. Meat and fiber intake and interaction with pattern recognition receptors (TLR1, TLR2, TLR4, and TLR10) in relation to colorectal cancer in a Danish prospective, case-cohort study. Am. J. Clin. Nutr. 2018, 107, 465-479. [CrossRef] [PubMed]

21. Andersen, V.; Kopp, T.I.; Tjonneland, A.; Vogel, U. No association between Hmox1 and risk of colorectal cancer and no interaction with diet and lifestyle factors in a prospective Danish case-cohort study. Int. J. Mol. Sci. 2015, 16, 1375-1384. [CrossRef] [PubMed]

22. Andersen, V.; Vogel, U. Systematic review: Interactions between aspirin, and other nonsteroidal anti-inflammatory drugs, and polymorphisms in relation to colorectal cancer. Aliment. Pharmacol. Ther. 2014, 40, 147-159. [CrossRef] [PubMed]

23. Andersen, V.; Vogel, U. Interactions between meat intake and genetic variation in relation to colorectal cancer. Genes Nutr. 2015, 10, 448. [CrossRef] [PubMed]

24. Andersen, V.; Holst, R.; Vogel, U. Systematic review: Diet-gene interactions and the risk of colorectal cancer. Aliment. Pharmacol. Ther. 2013, 37, 383-391. [CrossRef] [PubMed]

25. Nan, H.; Morikawa, T.; Suuriniemi, M.; Imamura, Y.; Werner, L.; Kuchiba, A.; Yamauchi, M.; Hunter, D.J.; Kraft, P.; Giovannucci, E.L.; et al. Aspirin use, 8q24 single nucleotide polymorphism rs6983267, and colorectal cancer according to CTNNB1 alterations. J. Natl. Cancer Inst. 2013, 105, 1852-1861. [CrossRef] [PubMed]

26. Lemaitre, R.N.; Johnson, C.O.; Hesselson, S.; Sotoodehnia, N.; McKnight, B.; Sitlani, C.M.; Rea, T.D.; King, I.B.; Kwok, P.Y.; Mak, A.; et al. Common variation in fatty acid metabolic genes and risk of incident sudden cardiac arrest. Heart Rhythm. 2014, 11, 471-477. [CrossRef] [PubMed]

27. Hadj Salem, I.; Kamoun, F.; Louhichi, N.; Trigui, M.; Triki, C.; Fakhfakh, F. Impact of single-nucleotide polymorphisms at the TP53-binding and responsive promoter region of BCL2 gene in modulating the phenotypic variability of LGMD2C patients. Mol. Biol. Rep. 2012, 39, 7479-7486. [CrossRef] [PubMed]

28. De Angelis, P.M.; Stokke, T.; Thorstensen, L.; Lothe, R.A.; Clausen, O.P. Apoptosis and expression of Bax, Bcl-x, and Bcl-2 apoptotic regulatory proteins in colorectal carcinomas, and association with p53 genotype/phenotype. Mol. Pathol. MP 1998, 51, 254-261. [CrossRef] [PubMed]

29. Takatsuno, Y.; Mimori, K.; Yamamoto, K.; Sato, T.; Niida, A.; Inoue, H.; Imoto, S.; Kawano, S.; Yamaguchi, R.; Toh, H.; et al. The rs6983267 SNP is associated with MYC transcription efficiency, which promotes progression and worsens prognosis of colorectal cancer. Ann. Surg. Oncol. 2013, 20, 1395-1402. [CrossRef] [PubMed]

30. Guillem, V.; Amat, P.; Collado, M.; Cervantes, F.; Alvarez-Larran, A.; Martinez, J.; Tormo, E.; Eroles, P.; Solano, C.; Hernandez-Boluda, J.C. Bcl2 gene polymorphisms and splicing variants in chronic myeloid leukemia. Leukemia Res. 2015. [CrossRef] [PubMed]

31. Wang, Y.P.; Zhang, J.; Zhu, H.Y.; Qian, C.L.; Liu, H.; Ji, F.; Shen, Z.Y. Common variation rs6983267 at 8q24.1 and risk of colorectal adenoma and cancer: Evidence based on 31 studies. Tumour. Biol. 2014, 35, 4067-4075. [CrossRef] [PubMed]

32. Tan, X.L.; Nieters, A.; Hoffmeister, M.; Beckmann, L.; Brenner, H.; Chang-Claude, J. Genetic polymorphisms in TP53, nonsteroidal anti-inflammatory drugs and the risk of colorectal cancer: Evidence for geneenvironment interaction? Pharmacogenet. Genom. 2007, 17, 639-645. [CrossRef] [PubMed]

33. Hong, S.P.; Ha, S.H.; Park, I.S.; Kim, W.H. Induction of apoptosis in colon cancer cells by nonsteroidal anti-inflammatory drugs. Yonsei Med. J. 1998, 39, 287-295. [CrossRef] [PubMed]

34. Andersen, V.; Ostergaard, M.; Christensen, J.; Overvad, K.; Tjonneland, A.; Vogel, U. Polymorphisms in the xenobiotic transporter multidrug resistance 1 (MDR1) gene and interaction with meat intake in relation to risk of colorectal cancer in a danish prospective case-cohort study. BMC Cancer 2009, 9, 407. [CrossRef] [PubMed]

35. Cook, R.T. Alcohol abuse, alcoholism, and damage to the immune system-A review. Alcohol. Clin. Exp. Res. 1998, 22, 1927-1942. [PubMed] 
36. Tjonneland, A.; Olsen, A.; Boll, K.; Stripp, C.; Christensen, J.; Engholm, G.; Overvad, K. Study design, exposure variables, and socioeconomic determinants of participation in diet, cancer and health: A population-based prospective cohort study of 57,053 men and women in denmark. Scand. J. Public Health. 2007, 35, 432-441. [CrossRef] [PubMed]

37. Barlow, W.E.; Ichikawa, L.; Rosner, D.; Izumi, S. Analysis of case-cohort designs. J. Clin. Epidemiol. 1999, 52, 1165-1172. [CrossRef]

38. Tjonneland, A.; Overvad, K.; Haraldsdottir, J.; Bang, S.; Ewertz, M.; Jensen, O.M. Validation of a semiquantitative food frequency questionnaire developed in Denmark. Int. J. Epidemiol. 1991, 20, 906-912. [CrossRef] [PubMed]

39. Foodcalc 1.3 computer program 1998. 2009. Available online: http://www.Foodcalc.Dk (accessed on 2 March 2019).

40. Prosky, L.; Asp, N.G.; Furda, I.; DeVries, J.W.; Schweizer, T.F.; Harland, B.F. Determination of total dietary fiber in foods and food products: Collaborative study. J. Assoc. Off. Anal. Chem. 1985, 68, 677-679. [PubMed]

41. Petersen, R.K.; Larsen, S.B.; Jensen, D.M.; Christensen, J.; Olsen, A.; Loft, S.; Nellemann, C.; Overvad, K.; Kristiansen, K.; Tjonneland, A.; et al. Ppargamma-PGC-1 $\alpha$ activity is determinant of alcohol related breast cancer. Cancer Lett. 2012, 315, 59-68. [CrossRef] [PubMed]

42. Miller, S.A.; Dykes, D.D.; Polesky, H.F. A simple salting out procedure for extracting DNA from human nucleated cells. Nucleic Acids Res. 1988, 16, 1215. [CrossRef] [PubMed]

43. Langholz, B.; Jiao, J. Computational methods for case-cohort studies. Comput. Stat. Data Anal. 2007, 51, 3737-3748. [CrossRef]

(C) 2019 by the authors. Licensee MDPI, Basel, Switzerland. This article is an open access article distributed under the terms and conditions of the Creative Commons Attribution (CC BY) license (http:/ / creativecommons.org/licenses/by/4.0/). 